\title{
ESTRUTURA CONCEITUAL DO INTEGRATED PROJECT DELIVERY (IPD) PRINCÍPIOS, CATALISADORES E PROPOSIÇÕES
}

\author{
CONCEPTUAL STRUCTURE OF INTEGRATED PROJECT DELIVERY (IPD): PRINCIPLES, \\ CATALYSTS AND PROPOSITIONS
}

\author{
Elisa Atália Daniel Muianga ${ }^{1}$, Ariovaldo Denis Granja $^{1}$
}

\section{RESUMO:}

Ao longo dos anos, pesquisas têm enfatizado a necessidade de adoção de alternativas da gestão de empreendimentos, como forma de superar os problemas vinculados aos métodos de contratação tradicionais. Métodos de contratação, como o Integrated Project Delivery (IPD) vêm ganhando interesse no setor da construção civil. Apesar do potencial do IPD, a introdução deste método na indústria da construção civil é desafiadora e se encontra em estágios iniciais. Os limites de conhecimento do IPD, até o momento, têm dificultado a sua aplicação em ambientes de produção de empreendimentos com pouca experiência sobre esta prática. Assim, considerando a necessidade de expandir o conhecimento sobre o tema, esta pesquisa objetiva analisar e sintetizar a informação relacionada ao IPD, identificar as associações entre os seus elementos e desenvolver proposições que orientam a sua aplicação. Como método de pesquisa, considerouse a abordagem qualitativa exploratória, com pesquisa de associação, sem interferência entre as variáveis. Foi também proposto o desenvolvimento de um mapa conceitual para compreensão da teoria. Os resultados da pesquisa apresentam a disposição dos elementos do IPD no processo de produção do empreendimento, quer seja no contexto contratual, operacional, organizacional e gerencial. As proposições reúnem informações sobre os benefícios possíveis de serem alcançados com a efetivação dos elementos do IPD.

PALAVRAS-CHAVE: Integrated Project Delivery; Integração; Colaboração; Acordo multipartes; Gestão de empreendimentos

\section{ABSTRACT:}

Over the years, studies have emphasized the necessity to adopt alternatives of project management, as a manner to overcome problems linked to traditional contracting methods. Contracting methods such as IPD (Integrated Project Delivery) have been gaining interest within of civil construction sector. However, despite the potential of IPD, the adoption of this method in construction industry is a challenging and still in its early stages. The limited knowledge of IPD so far have discouraged its application in project production environments with little experience through this practice. Thus, considering the need to expand knowledge of IPD, this research aims to analyse and synthesise information related to IPD, identify the associations between its elements and develop propositions in order to guide its application. As a research method, the exploratory qualitative approach was considered for the assessment of the association between IPD's elements, without considering interference between them. In addition, a conceptual map was proposed for the visual representation of the understanding of the theory. The research results show the disposition of IPD elements within of project production process, whether in the contractual, operational, organizational and managerial context. The propositions gather information on the possible benefits to be achieved by adopting IPD elements.

KEYWORDS: Integrated Project Delivery; Integration; Collaboration; Multipart agreements; Project management.
Fonte de Financiamento: Coordenação de Aperfeiçoamento de Pessoal de Nivel Superior - Brasil (CAPES) - Código de Financiamento 001

Conflito de Interesse: Declara não haver.

Submetido em: 02/03/2020 Aceito em: 01/02/2021 


\section{INTRODUÇÃO}

Organizações de diferentes setores industriais têm adotado alternativas para impulsionar e melhorar os processos de produção, e ofertar produtos que satisfaçam as exigências e demandas do mercado atual (ELY, 2016). Neste contexto, observa-se que a construção civil é um dos setores industriais que tem se mantido obsoleto quanto aos avanços da modernização da produção (MIHIC; SERTIC; ZAVRSKI, 2014; KIM et al., 2016). É visto que grande parte dos empreendimentos são desenvolvidos a partir de métodos de contratação tradicionais, com forte predominância pela aplicação do Design-Bid-Build (DBB) (HOSSEINI et al., 2016; PARK; KWAK, 2017).

Ao longo dos anos, pesquisas têm enfatizado a necessidade de adoção de alternativas na produção de empreendimentos, como forma de superar os problemas vinculados aos métodos de contratação tradicionais, que já foram extensamente discutidos na literatura (ex.:NAWI et al., 2014; HOSSEINI et al., 2018, RAHIM et al., 2016; ROY et al., 2017). No entanto, em uma análise mais abrangente do atual e predominante cenário da produção de empreendimentos no setor da construção civil, cujo processo é caracterizado por fases distintas e sequenciadas, a falta de conhecimento sobre novos conceitos de produção, somados a paradigmas culturais vigentes, podem limitar a busca e adoção dessas novas abordagens (MUIANGA, 2018). Neste sentido, observa-se que um dos principais desafios que o setor da construção civil enfrenta é a falta de oportunidade para acoplar serviços de pré-construção e para promover o envolvimento de diferentes frentes nos estágios iniciais de empreendimentos (AZHAR; KANG; AHMAD, 2014; ELY, 2016; HOSSEINI et al., 2018). Consequentemente, vários dos processos de produção falham na avaliação detalhada do escopo, o que dificulta o alcance das metas reais do empreendimento (LEE et al., 2014; JADIDOLESLAMI et al., 2019).

Assim, vários estudos têm recomendado a introdução de métodos de contratação com gestão integrada, como mecanismo para estabelecer estruturas de produção colaborativas e serviços de pré-construção já nas fases iniciais dos empreendimentos (MOLLAOGLU-KORKMAZ; MILLER; SUN, 2014; HALL; SCOTT, 2019; ENGEB $\emptyset$ et al., 2020). Neste contexto, métodos de contratação como o IPD (Integrated Project Delivery) vêm se destacando e ganhando interesse no setor da construção civil (RACHED et al., 2014; BIGELOW et al., 2015; RAHIM et al., 2016; OSBURN et al., 2018). 0 IPD foi proposto pelo AIA (American Institute of Architects) e é um modelo de gestão de empreendimentos que utiliza princípios de gerenciamento para integração de pessoas, sistemas, estruturas de negócios e práticas profissionais, em um processo colaborativo, de modo a aprimorar os resultados da produção (AIA, 2007a).

O IPD foi concebido sob a perspectiva de alinhar a meta do empreendimento com os interesses de todas as partes interessadas (AIA, 2012). É baseado fundamentalmente no ambiente de produção colaborativo e integrado, com o envolvimento em estágios iniciais, isto é, na fase de concepção, no mínimo, o projetista principal, o construtor principal e o proprietário, que constituem os participantes-chave do empreendimento (LIU et. al.; 2013; OSBURN et al., 2018). A represerntação gráfica da "MacLeamy Curve" (Figura 1) evidencia o envolvimento antecipado no IPD, baseado na tomada de decisões importantes do projeto em estágios iniciais, que oportunamente podem influenciar na maximização das metas, e redução do custo das alterções do projeto (AIA, 2007a). 


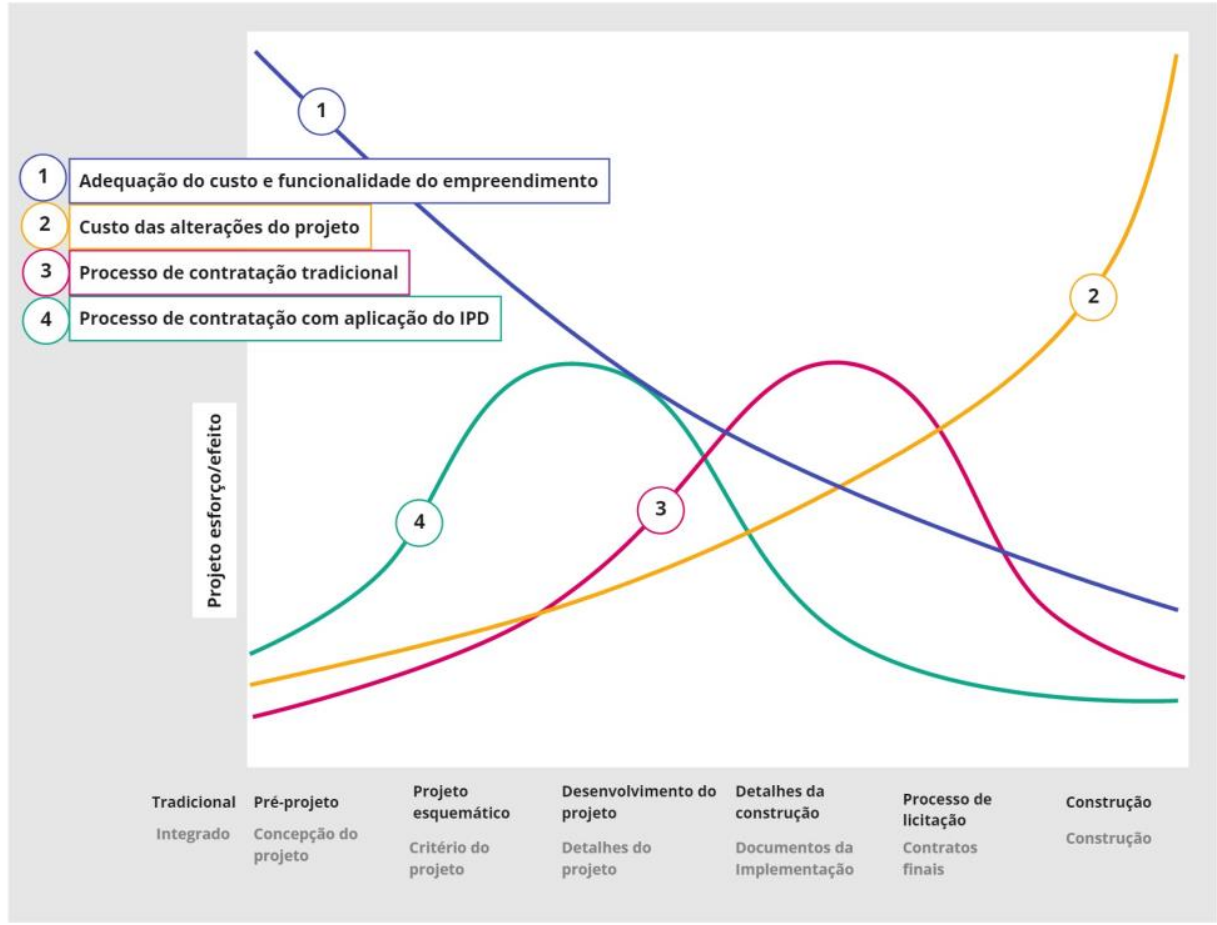

As diferenças relacionadas às fases iniciais de um empreendimento com a adoção do método de contratação tradicional, e, alternativamente, com o IPD, podem ser observadas na Figura 2. As decisões iniciais tomadas pelos participantes-chave definem o processo, e, consequentemente, influenciam em todo o empreendimento (FISCHER et al., 2014). Em geral, devido à eficiência da estrutura organizacional do IPD, os serviços de pré-construção são aplicados para o desenvolvimento do empreendimento em um ambiente de produção integrado, com oportunidades para um planejamento detalhado e para a inclusão de ideias inovadoras desde o início (DARRINGTON, 2013).

Para a contratação, ainda no estágio inicial, é desenvolvida uma dinâmica com o propósito de extrair informações sobre os requisitos e necessidades do proprietário em relação ao empreendimento (KNAPP; LONG; HOWELL, 2014). Os dados gerados na dinâmica são aplicados na análise inicial da viabilidade do empreendimento, de acordo com a disponibilidade financeira do proprietário (MOYLAN; ARAFAH, 2017). Posteriormente, pela necessidade de incluir dados cada vez mais precisos nos documentos do empreendimento, são vinculadas as demais partes interessadas ao processo (FISCHER et al., 2014). Para isso, é desenvolvido um workshop contratual (OSBURN et al., 2018).

Durante o workshop contratual, os participantes, que podem ser indicados pelo projetista e construtor principal, ou mesmo pelo proprietário, são selecionados de acordo com as suas qualificações (MESA; MOLENAAR; ALARCÓN, 2016). As partes interessadas selecionadas podem compor diferentes disciplinas do projeto, consultores, coordenadores, subempreiteiros, fornecedores, agências, e outras equipes necessárias (AIA, 2007a; AIA et al., 2010). Com a seleção prévia das partes interessadas, é desenvolvida a dinâmica do alinhamento das perspectivas dos envolvidos em relação ao empreendimento, é efetuado o esboço do projeto, são analisadas as sugestões e metas, e efetuadas as revisões e negociações finais (OSBURN et al., 2018). No final, quando todos os itens anteriores são estiverem concluídos, segue-se para a celebração do contrato final do IPD firmado entre todas as partes interessadas, disponíveis para participar no empreendimento (FISCHER et al., 2014).
Figura 1. Representação

MacLeamy Curve

Fonte: Autores, baseado em AIA (2007a) 
Figura 2. Representação das

diferenças entre um

processo com contrato tradicional e contrato IPD

Fonte: Autores, baseado em Darrington (2009)

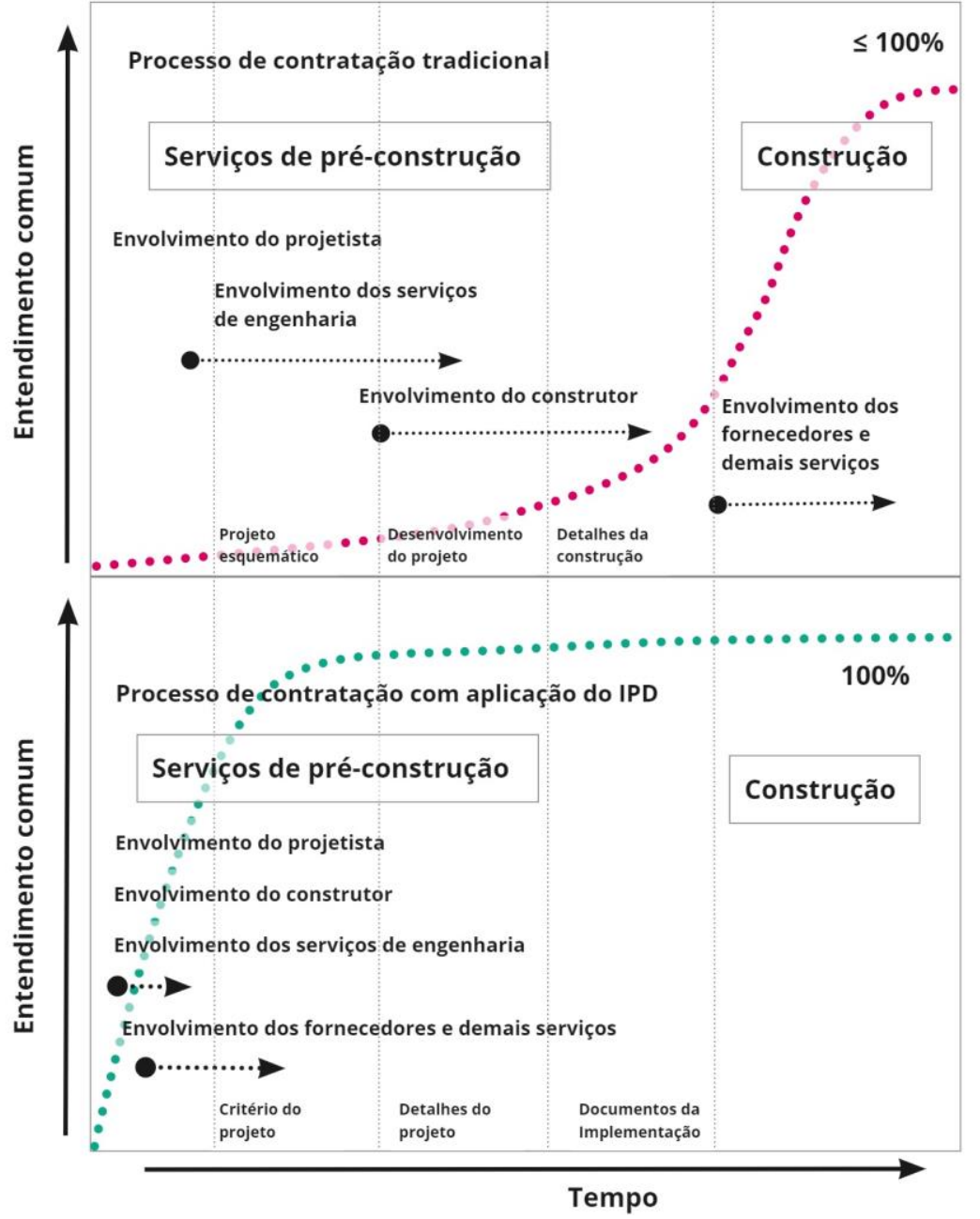

Para a contratação, ainda no estágio inicial, é desenvolvida uma dinâmica com o propósito de extrair informações sobre os requisitos e necessidades do proprietário em relação ao empreendimento (KNAPP; LONG; HOWELL, 2014). Os dados gerados na dinâmica são aplicados na análise inicial da viabilidade do empreendimento, de acordo com a disponibilidade financeira do proprietário (MOYLAN; ARAFAH, 2017). Posteriormente, pela necessidade de incluir dados cada vez mais precisos nos documentos do empreendimento, são vinculadas as demais partes interessadas ao processo (FISCHER et al., 2014). Para isso, é desenvolvido um workshop contratual (OSBURN et al., 2018).

Durante o workshop contratual, os participantes, que podem ser indicados pelo projetista e construtor principal, ou mesmo pelo proprietário, são selecionados de acordo com as suas qualificações (MESA; MOLENAAR; ALARCÓN, 2016). As partes interessadas selecionadas podem compor diferentes disciplinas do projeto, consultores, coordenadores, subempreiteiros, fornecedores, agências, e outras equipes necessárias (AIA, 2007a; AIA et al., 2010). Com a seleção prévia das partes interessadas, é desenvolvida a dinâmica do alinhamento das perspectivas dos envolvidos em relação ao empreendimento, é efetuado o esboço do projeto, são analisadas as sugestões e metas, e efetuadas as revisões e negociações finais (OSBURN et al., 2018). No final, quando todos os itens anteriores são estiverem concluídos, segue-se para a celebração do contrato final do IPD firmado entre todas as partes interessadas, disponíveis para participar no empreendimento (FISCHER et al., 2014). 
Evidencia-se que em sua abordagem principal, o IPD procura superar sistematicamente os problemas relacionados às questões organizacionais e comerciais do empreendimento (DARRINGTON et al., 2009). Por essa razão, o IPD requer um alto nível de envolvimento de todas as partes interessadas na mudança de paradigma, na percepção da interação das equipes, e nas expetativas individuais de cada parte envolvida na produção (FRANZ; LEICHT, 2012).

A difusão de pesquisas sobre o IPD demonstra a recorrência da discussão sobre a temática (OSBURN et al., 2018). O IPD tem atraído interesse, tanto do meio acadêmico, como do setor industrial da construção civil (KIM et al., 2016; CHOI et al., 2019), sendo visto como uma alternativa para superar problemas recorrentes na construção civil, e limitações vinculadas aos métodos de contratação tradicionais (ROY et al., 2017; ZHANG; HUANG; PENG, 2018).

Entretanto, apesar do potencial que o IPD apresenta, a introdução deste modelo na indústria da construção civil é desafiadora e ainda se encontra em estágios iniciais (AZHAR; KANG; AHMAD, 2014; HAMZEH et al., 2019). Ainda que pouco aplicado, a maior parte dos empreendimentos desenvolvidos com adoção do IPD foram de natureza privada, localizados em países onde há mais potencialidade da adoção de métodos de contratação que enfatizam a modernização do processo de produção na construção civil (MESA; MOLENAAR; ALARCóN, 2016; PISHDAD-BOZORGI, 2017; FERNANDO et al., 2017).

Por outro lado, embora diversas pesquisas enumerem características e elementos do IPD que podem ser adotados para melhorar a produção de empreendimentos, ainda há falta de orientações sobre como estes podem ser aplicados de modo gradual e evolutivo (OSBURN et al., 2018; HAMZEH et al., 2019). Neste sentido, destaca-se a necessidade do alinhamento conceitual dos elementos do IPD, e a relação de abrangência entre eles (MOLLAOGLUKORKMAZ; MILLER; SUN, 2014; OSBURN et al., 2018). Além disso, os reais benefícios do IPD em prática ainda são pouco compreendidos na indústria da construção civil (DE MARCO; KARZOUNA, 2018; WHANG; PARK; KIM, 2019; TENG et al., 2019). Os limites de conhecimento e aplicabilidade do IPD têm dissuadido a adoção dos seus elementos em ambientes de produção de empreendimentos com pouca experiência com esta prática (LAURENT; LEICHT, 2019; ABDIRAD; DOSSICK, 2019; DURDYEV et al., 2019).

Considerando os benefícios que o IPD pode proporcionar à gestão de empreendimentos do setor, associada à necessidade de aplicação de mudanças significativas para a sua gestão em termos de melhorias e modernização do processo de produção, a partir de elementos que enfatizam a colaboração efetiva em estágios iniciais, definiram-se como questões de pesquisa: (i) que contribuições as pesquisas proporcionaram para a formação de conhecimento em relação ao IPD?; (ii) como o IPD pode ser fortalecido a partir da compreensão de seus princípios teóricos e metodológicos para aplicação em empreendimentos do setor da construção civil?; (iii) quais são as associações sem interferência existentes entre os seus elementos?; (iv) quais benefícios a aplicação dos elementos do IPD pode proporcionar na prática da gestão de empreendimentos no setor?

A partir das questões de pesquisa declaradas, os objetivos desta pesquisa são: analisar e sintetizar a informação relacionada ao IPD; identificar as associações sem interferência entre os elementos que constituem o IPD; desenvolver proposições orientadoras a partir de um mapa conceitual sobre o IPD, de modo a caracterizar os potenciais resultados que podem ser alcançados com a sua adoção em empreendimentos do setor da construção civil.

Este documento está organizado em cinco seções. Na segunda seção, apresentamos o método de pesquisa, e destacamos os procedimentos para identificar as associações dos elementos do IPD. Na quarta seção, apresentamos a contextualização do IPD, e a análise da associação dos seus elementos. Na quinta seção, apresentamos a discussão sobre a construção do mapa 
conceitual, e os principais resultados da pesquisa. Na última seção, apresentamos as conclusões e discutimos as contribuições da pesquisa.

\section{MÉTODO DE PESQUISA}

A pesquisa visa avaliar e sintetizar a informação sobre o IPD. Neste sentido, considerou-se para o estudo a abordagem qualitativa exploratória, com pesquisa de associação sem interferência entre as variáveis. A pesquisa de associação sem interferência entre as variáveis foca nas relações entre variáveis. Neste sentido, considera-se que diferentes variáveis não se interferem, no entanto, podem ser associadas, com possibilidade de análise da correlação e tendência central, de forma qualitativa (VOLPATO, 2015).

\section{CARACTERIZAÇÃO DA PESQUISA}

A pesquisa qualitativa é focada na compreensão e explicação profunda da relação das variáveis, a partir de dados não quantificáveis (GOLDENBERG, 1997). Como resultado, pesquisas qualitativas proporcionam flexibilidade na obtenção das respostas, com informação e síntese verticalizada ao objeto do estudo (DIAS, 2000). Por outro lado, a pesquisa exploratória tem por objetivo tornar o problema mais explícito e construir hipóteses, por meio do aprimoramento de ideias (GIL, 2007; GERHARDT; SILVEIRA, 2009). Técnicas como o levantamento bibliográfico, entrevistas com pessoas experientes com a temática analisada, e análise de exemplos que estimulem a compreensão constituem parte das técnicas de coleta de dados vinculadas à pesquisa exploratória (SELLTIZ et al., 1967).

A entrevista é um instrumento de coleta de dados que pode ser aplicado tanto em pesquisas qualitativas e quantitativas, dependendo das caraterísticas dos dados a serem coletados (FIGUEIREDO, 2004). Assim, para o desenvolvimento de proposições que auxiliam a obter a compreensão teórica sobre o IPD, foram desenvolvidas entrevistas interativas, realizadas de forma síncrona. Para maior efetividade da entrevista foi enviado um protocolo com informação técnica sobre o tema, e objetivo do processo antes da interação.

Fizeram parte deste processo, uma Professora associada, do Departamento de Engenharia Civil, Construção e Ambiental, de uma Universidade norte-americana. A pesquisadora tem realizado pesquisas com ênfase em: construção civil, planejamento e controle da produção, construção enxuta e cadeia de suprimentos. Além disso conduz pesquisas no assunto IPD. 0 segundo pesquisador é Professor Titular, do Departamento de Engenharia Civil de uma Universidade do nordeste do Brasil. Suas pesquisas têm abordado temas, tais como: construção civil, construção enxuta, estratégia de produção, estratégia empresarial e pequenas empresas. A interação com estes pesquisadores permitiu o desenvolvimento do mapa conceitual a partir da compreensão da informação coletada na literatura. Finalmente, estes mesmos pesquisadores contribuíram com a avaliação final da proposta do mapa conceitual.

\section{MAPA CONCEITUAL}

Mapa conceitual é uma representação gráfica, ou fotoleitura de visualização de relacionamentos significativos entre conceitos, por meio de palavras e frases que expressam o real sentido da ação do contexto em análise (CARVALHO et al. 2016 e RUIZ-MORENO et al. 2007). Os mapas conceituais apresentam uma análise de conteúdo qualitativo, que procura evidenciar a percepção individual ou coletiva que se tem sobre um assunto específico (SOUZA; BORUCHOVITCH, 2010). Neste sentido, os mapas conceituais configuram um mecanismo de 
aprendizagem, com representação visual da compreensão de uma nova teoria (MAXWELL, 2012).

Os mapas conceituais (Figura 3) são organizados a partir de um conjunto de conceitos (palavras-chaves) e relações lógicas (frases ou palavras que unem os conceitos), podendo se resumir pela forma conceito-relação-conceito (YOSHIMOTO et al. 2016). A relação entre conceitos formados por palavras é também designada conector (NOVAK; CAÑAS, 2008).

A estrutura hierárquica inicia com um conceito-chave (GARABET; MIRON, 2010). Após o conceito-chave, são dispostos conceitos mais gerais de forma hierárquica, geralmente projetado para ler de baixo para cima (CARVALHO et al. 2016). Para vincular os conceitos são aplicadas frases de ligação.

As frases de ligação descrevem o tipo de relacionamento entre dois conceitos, e aparecem na linha que os conecta (SOUZA; BORUCHOVITCH, 2010). A proposição é construída a partir da relação entre dois ou mais conceitos, com formação de sentenças significativas (RUIZ-MORENO et al. 2007).

No entanto, a estrutura de um mapa conceitual não se limita a um padrão. Mapas conceituais podem assumir uma abordagem de forma livre, iniciado do centro, e se espalhando para fora, ou com disposição para ler de cima para baixo (MATTOS et al., 2020).

Os mapas conceituais facilitam a compreensão do assunto, integram conceitos, sintetizam informação e formam uma nova ideia sobre o assunto, proporcionando compreensão clara sobre conceitos e ideias complexas, ao mesmo tempo que auxiliam na difusão da criatividade (GARABET; MIRON, 2010). No geral, os mapas conceituais são fundamentais para o desenvolvimento de uma teoria de aprendizagem significativa (RUIZ-MORENO et al. 2007).

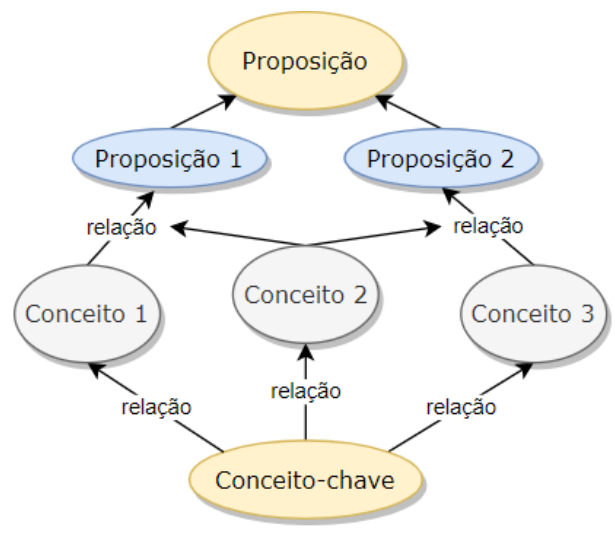

Assim, para esta pesquisa, o mapa conceitual foi proposto para auxiliar na percepção da relação entre os conceitos e princípios do IPD, e no desenvolvimento de proposições, por meio de elementos coesivos extraídos da literatura. Para a elaboração do mapa conceitual foi primeiramente identificado o conceito principal da pesquisa (IPD). Foi então desenvolvido um brainstorming em torno ao IPD a partir da informação sobre os seus elementos dispostos na literatura. Foi então avaliada a relação entre os conceitos e adicionadas palavras que os conectam. Dessa forma foram agrupados princípios e catalisadores, e atribuído o domínio. As proposições desenvolvidas a partir da análise da informação coletada na literatura, junto com as entrevistas interativas, resultaram na representação visual da organização e abrangência dos elementos do IPD, demonstrado por meio do mapa conceitual. 0 mapa foi construído com a participação de dois pesquisadores (já descritos anteriormente) com experiência em relação à gestão de empreendimentos.
Figura 3. Representação de um mapa conceitual

Fonte: Autores, baseado em Yoshimoto et al. (2016) 


\section{Etapas para o desenvolvimento da pesquisa}

A pesquisa envolveu três etapas sequenciais (Figura 4). Na primeira etapa foi desenvolvida a análise dos estudos que abordam IPD. Neste processo, foram identificados os principais estudos e manuais que apresentam elementos do IPD. Na segunda etapa, foi efetuada a análise dos elementos do IPD com auxílio dos manuais do AIA.

Figura 4. Etapas do desenvolvimento da pesquisa.

Fonte: Autores

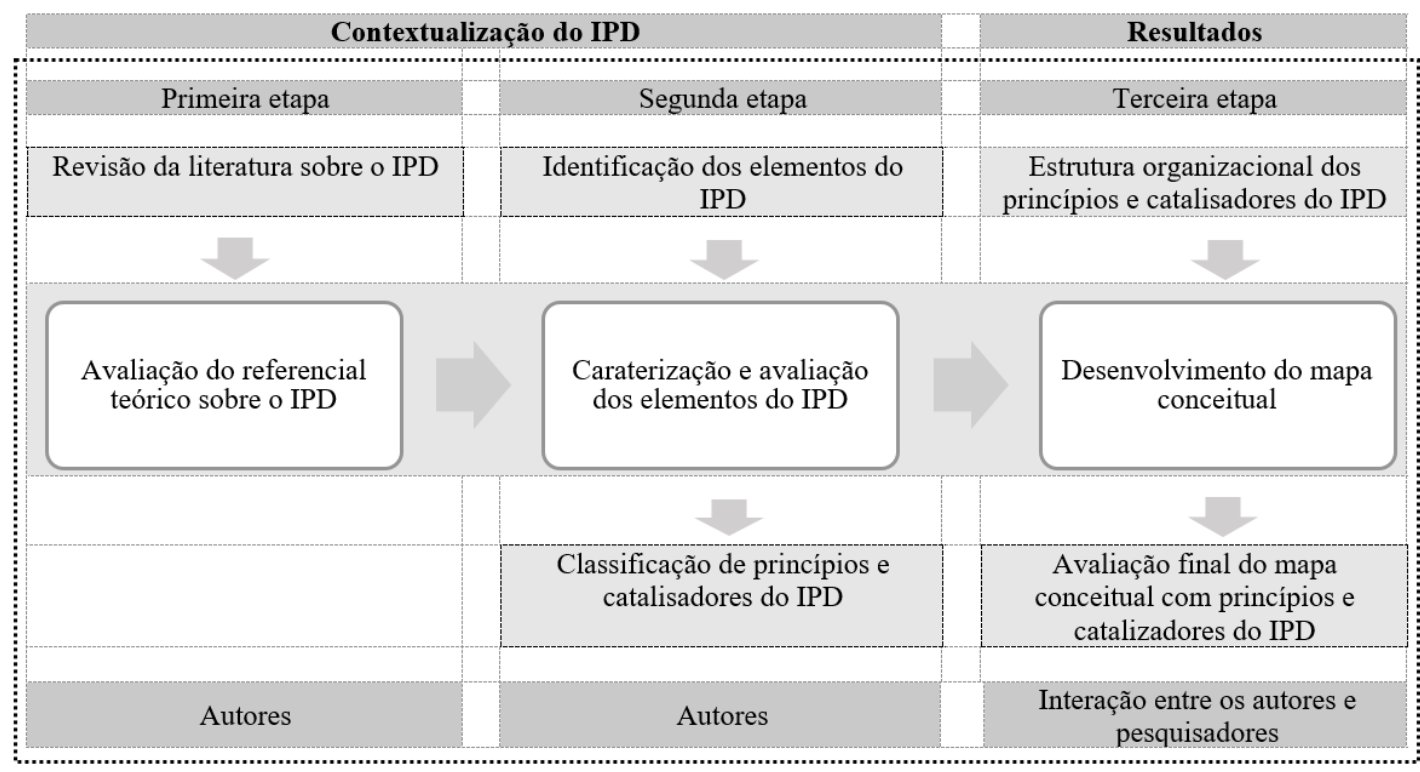

Na terceira etapa foi desenvolvida a interação entre dois pesquisadores, já apresentados no "item" (caracterização da pesquisa), e os moderadores (autores da pesquisa). A interação foi desenvolvida com o propósito de construir um conhecimento a partir da compreensão da informação coletada na literatura sobre como os princípios e catalisadores são organizados, e como se dá a interferência das suas ações. Para isso, foram desenvolvidos ciclos interativos de forma síncrona virtual com os pesquisadores para discussão e obtenção de consensos entre as opiniões e conhecimento apresentado. 0 resultado desta etapa é a representação visual do mapa conceitual.

\section{CONTEXTUALIZAÇÃO DO IPD}

Para a contextualização do IPD, foi desenvolvida uma análise crítica de pesquisas que identificaram os elementos que compõem esta abordagem. As informações coletadas dos estudos foram posteriormente avaliadas para a caracterização dos elementos do IPD.

\section{Avaliação do referencial teórico sobre o IPD: identificação dos seus elementos}

Para a identificação de princípios e catalisadores do IPD, primeiro efetuou-se uma análise do que já havia sido publicado na literatura sobre a temática. Dos estudos avaliados destacaramse os manuais do American Institute of Architects (AIA: 2007a, 2007b, 2010, 2011 e 2012), e os artigos que identificam os elementos do IPD (GHASSEMI; BECERIK-GERBER, 2011; FRANZ; LEICHT, 2012; NAWI; NIFA; AHMED, 2014; IOPPI; FORMOSO; ISATTO, 2015; MOYLAN; ARAFAH 2017). 


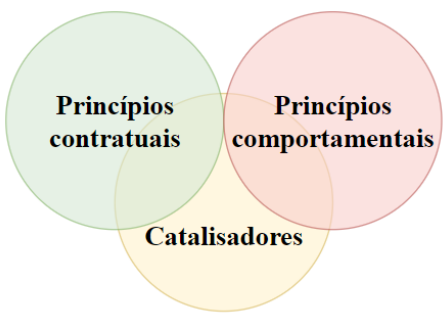

Os elementos do IPD são classificados na literatura como princípios contratuais e comportamentais (Contractual e Behavioural Principles) (Figura 5). Além disso, existe uma terceira classificação com elementos designados catalisadores (catalysts) (AIA, 2012; AIA et. al, 2010).

A literatura sobre o IPD é pouco clara em relação aos seus princípios e catalisadores. Assim, a distinção entre princípios e catalisadores é pouco evidenciada, sendo em maioria atribuída à categoria de princípios para todos os elementos. Observa-se, ainda, que os princípios são elementos principais do IPD, que se constituem em requisitos obrigatórios, para que se considere um empreendimento com a total aplicação do modelo (AIA, 2012; AIA, 2011; AIA et. al, 2010; AIA, 2007a; AIA, 2007b). Por outro lado, os catalisadores são classificados como elementos secundários, que têm como função o aprimoramento dos princípios do IPD (AIA et. al, 2010).

Para a identificação dos elementos do IPD, efetuou-se uma comparação entre os artigos publicados que retratam princípios ou necessidades do IPD. Constatou-se que os manuais do AIA (2010 e 2012) são mais concisos em relação aos princípios. Assim, a informação coletada a partir destes manuais serviu como base para a identificação dos princípios. Além disso, para facilitar a avaliação da informação, foi realizada uma compilação das terminologias dos elementos do IPD utilizados nos trabalhos analisados. Para melhor assimilação, foi atribuída uma denominação em português para cada um dos princípios (). ).

\begin{tabular}{|c|c|c|}
\hline & Princípios do IPD & Autores \\
\hline \multirow{4}{*}{ 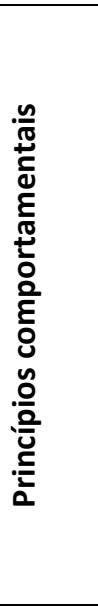 } & $\begin{array}{l}\text { Respeito mútuo e confiança (mutual } \\
\text { respect and trust). }\end{array}$ & $\begin{array}{l}\text { Franz; Leicht (2012); Nawi; Nifa; Ahmed } \\
\text { (2014); Moylan; Arafah (2017); AIA (2012); } \\
\text { AIA (2011); AIA (2010); AIA (2007a); AIA } \\
\text { (2007b). }\end{array}$ \\
\hline & $\begin{array}{l}\text { Alinhamento de metas nas fases iniciais } \\
\text { do empreendimento (early goal } \\
\text { definition or aligned project goals or } \\
\text { Jointly developed project target criteria) }\end{array}$ & $\begin{array}{l}\text { Ghassemi; Becerik-Gerber (2011); Franz; } \\
\text { Leicht (2012); Nawi; Nifa; Ahmed (2014); } \\
\text { loppi; Formoso; Isatto (2015); Moylan; } \\
\text { Arafah (2017); AIA (2012); AIA (2011); AIA } \\
\text { (2010); AIA (2007a); AIA (2007b). }\end{array}$ \\
\hline & $\begin{array}{l}\text { Comunicação aberta (open } \\
\text { communication/ networked sharing). }\end{array}$ & $\begin{array}{l}\text { Nawi; Nifa; Ahmed (2014); Moylan; Arafah } \\
\text { (2017); AIA (2012); AIA (2011); AIA (2010); } \\
\text { AIA (2007a); AIA (2007b). }\end{array}$ \\
\hline & $\begin{array}{l}\text { Disposição para o trabalho colaborativo } \\
\text { (willing to collaborate) }\end{array}$ & AIA (2012); AIA (2011); AIA (2010). \\
\hline 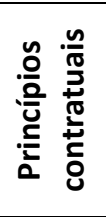 & $\begin{array}{l}\text { Compartilhamento de riscos financeiros, } \\
\text { benefícios e recompensas (shared } \\
\text { financial risk, benefit and reward) }\end{array}$ & $\begin{array}{l}\text { Ghassemi; Becerik-Gerber (2011); Franz; } \\
\text { Leicht (2012); Nawi; Nifa; Ahmed (2014); } \\
\text { Moylan; Arafah (2017); AIA (2012); AIA } \\
\text { (2011); AIA (2010); AIA (2007a); AIA } \\
\text { (2007b). }\end{array}$ \\
\hline
\end{tabular}

Figura 5. Classificação dos elementos do IPD.

Fonte:

Autores, baseado no AIA (2010, 2012).

Tabela 1. Princípios do IPD

Fonte: Autores, baseado na literatura. 
Tabela 1. Princípios do IPD (Continuação)

Fonte: Autores, baseado na literatura.

Catalisadores do IPD

Fonte: Autores, baseado na literatura.

\begin{tabular}{|c|c|}
\hline Princípios do IPD & Autores \\
\hline $\begin{array}{l}\text { Termo de responsabilidade entre os } \\
\text { participantes-chaves '(Liability Waivers } \\
\text { between Key Participants). }\end{array}$ & $\begin{array}{l}\text { Ghassemi; Becerik-Gerber (2011); AIA } \\
\text { (2012); AIA (2011); AIA (2010). }\end{array}$ \\
\hline $\begin{array}{l}\text { Vinculação e igualdade contratual entre } \\
\text { os participantes-chaves (Key Participants } \\
\text { Bound Together as Equals). }\end{array}$ & AIA (2012); AIA (2011); AIA (2010). \\
\hline $\begin{array}{l}\text { Envolvimento antecipado dos } \\
\text { participantes-chaves (early involvement } \\
\text { of key participants). }\end{array}$ & $\begin{array}{l}\text { Ghassemi; Becerik-Gerber (2011); Franz; } \\
\text { Leicht (2012); Nawi; Nifa; Ahmed (2014); } \\
\text { loppi; Formoso; Isatto (2015); AIA (2012); } \\
\text { AIA (2011); AIA (2010); AIA (2007a). }\end{array}$ \\
\hline $\begin{array}{l}\text { Inovação e decisões colaborativas } \\
\text { (collaborative innovation and decision } \\
\text { making) }\end{array}$ & $\begin{array}{l}\text { Ghassemi; Becerik-Gerber (2011); Franz; } \\
\text { Leicht (2012); Nawi; Nifa; Ahmed (2014); } \\
\text { loppi; Formoso; Isatto (2015); AIA (2012); } \\
\text { AIA (2011); AIA (2010); AIA (2007a); AIA } \\
\text { (2007b). }\end{array}$ \\
\hline $\begin{array}{l}\text { Transparência fiscal (fiscal transparency } \\
\text { between key participants) }\end{array}$ & AIA (2012); AIA (2011); AIA (2010). \\
\hline
\end{tabular}

Durante a avaliação dos elementos do IPD, houve um esforço para distinguir os catalisadores dos princípios. Isso deveu-se ao fato de que a maior parte dos estudos publicados sobre o IPD mesclam esses dois elementos como sendo a mesma coisa. No entanto, o AIA et al. (2010) particulariza a classificação dos catalisadores, designando-os como "Catalysts for IPD". Além do AIA et al. (2010), o IPD (2012) inclui, além dos princípios, as denominadas estratégias (IPD Strategies). Neste contexto, observou-se que uma parte das estratégias apresentadas para efetivação dos princípios no AIA (2012) também são consideradas catalisadores no AIA et al. (2010). Assim, a informação extraída nesses dois manuais deu origem à classificação proposta dos catalisadores do IPD (Tabela 2).

\begin{tabular}{ll}
\hline Catalisadores ou estratégias & Autores \\
\hline Co-location. & AIA (2010); AIA (2012).
\end{tabular}

Forte liderança e organização (strong leadership and organization)

Nawi; Nifa; Ahmed (2014); loppi; Formoso; Isatto (2015); Moylan; Arafah (2017); AIA (2012); AIA (2007a); AIA (2007b). AIA (2010).

Plano de incentivos financeiros vinculados às metas (financial incentives tied to goals)

Relacionamento pré-existente entre as partes AIA (2012). interessadas (pre-existing relationships between parties).

Proteção contra litígios (processos) e seguro AIA (2012). integrado do empreendimento (protection from litigation and integrated project insurance).

Acordos multipartes, podendo ser contratos relacionais (multi-party agreement or relational contracts).
Ghassemi; Becerik-Gerber (2011); AIA (2010); AIA (2012). 


\begin{tabular}{|c|c|}
\hline Catalisadores ou estratégias & Autores \\
\hline $\begin{array}{l}\text { Adoção de ferramentas de execução com base } \\
\text { na construção enxuta (implementation tools, } \\
\text { i.e. Lean construction processes) }\end{array}$ & AIA (2010); AIA (2012). \\
\hline $\begin{array}{l}\text { Esforços intensivos de planejamento } \\
\text { (intensified planning). }\end{array}$ & $\begin{array}{l}\text { Nawi; Nifa; Ahmed (2014); Moylan; Arafah } \\
\text { (2017); AIA (2012); AIA (2007a); AIA } \\
\text { (2007b). }\end{array}$ \\
\hline $\begin{array}{l}\text { Tecnologias apropriadas (appropriate } \\
\text { technology). }\end{array}$ & $\begin{array}{l}\text { Franz; Leicht (2012); Nawi; Nifa; Ahmed } \\
\text { (2014); Moylan; Arafah (2017); AIA (2010); } \\
\text { AIA (2012); AIA (2007a); AIA (2007b). }\end{array}$ \\
\hline
\end{tabular}

Em relação aos catalisadores, constatou-se que estes apresentam um caráter flexível, uma vez que as suas aplicações se vinculam às necessidades do empreendimento, disponibilidade de recursos e experiência das partes interessadas em relação ao IPD, e as suas reais necessidades, desde que estes impulsionem a efetivação dos princípios (MUIANGA, 2018). Assim, pode-se inferir que a seleção dos catalisadores não se restringe apenas ao indiciado nos manuais do AIA. Portanto, diferentes alternativas podem ser adotadas, o que pode facilitar a adequação de uso dos mesmos, dependendo do ambiente e oportunidades que o processo de produção do empreendimento proporciona.

\section{Caracterização e avaliação da relação dos elementos do IPD}

Para a análise da relação entre princípios e catalisadores, procurou-se sintetizar as informações que descrevem esses elementos na literatura. Desse modo, os princípios e catalisadores foram dispostos de acordo com a caracterização que os correlacionam (Tabela $3)$.

\begin{tabular}{|c|c|c|c|}
\hline Princípio & Catalisador & Caracterização & Referências \\
\hline $\begin{array}{l}\text { Respeito mútuo } \\
\text { e confiança }\end{array}$ & $\begin{array}{l}\text { Relacionament } \\
\text { o pré-existente } \\
\text { entre as partes } \\
\text { interessadas }\end{array}$ & $\begin{array}{l}\text { O respeito mútuo e confiança são } \\
\text { facilmente adotados entre partes } \\
\text { interessadas que tenham trabalhado } \\
\text { anteriormente em ambiente colaborativo. } \\
\text { Neste contexto, há facilidade de percepção } \\
\text { sobre as metas, e do estabelecimento da } \\
\text { confiança para a condução do } \\
\text { empreendimento. }\end{array}$ & $\begin{array}{l}\text { Aziz, Hafez, } \\
\text { 2013; Alarcón, } \\
\text { Mesa, Howell, } \\
\text { 2013; Fischer } \\
\text { et al., 2014; } \\
\text { Suttie, 2013. }\end{array}$ \\
\hline $\begin{array}{l}\text { Alinhamento de } \\
\text { metas nas fases } \\
\text { iniciais do } \\
\text { empreendimento }\end{array}$ & $\begin{array}{l}\text { Plano de } \\
\text { incentivos } \\
\text { financeiros } \\
\text { vinculados às } \\
\text { metas }\end{array}$ & $\begin{array}{l}\text { As metas mútuas são alinhadas com os } \\
\text { interesses individuais das partes } \\
\text { interessadas, e acordadas logo no início. O } \\
\text { plano de incentivo pode ser vinculado às } \\
\text { metas para impulsionar o desempenho das } \\
\text { equipes. }\end{array}$ & $\begin{array}{l}\text { AIA et. Al., } \\
\text { 2010; AIA, } \\
\text { 2007a; AIA, } \\
2012 .\end{array}$ \\
\hline
\end{tabular}

Tabela 2.

Catalisadores do IPD

(Continuação)

Fonte: Autores, baseado na literatura.
Tabela 3. Disposição e caracterização dos princípios e catalisadores do IPD.

Fonte: Autores. 
Tabela 3. Disposição e caracterização dos princípios e catalisadores do IPD. (Continuação)

Fonte: Autores.

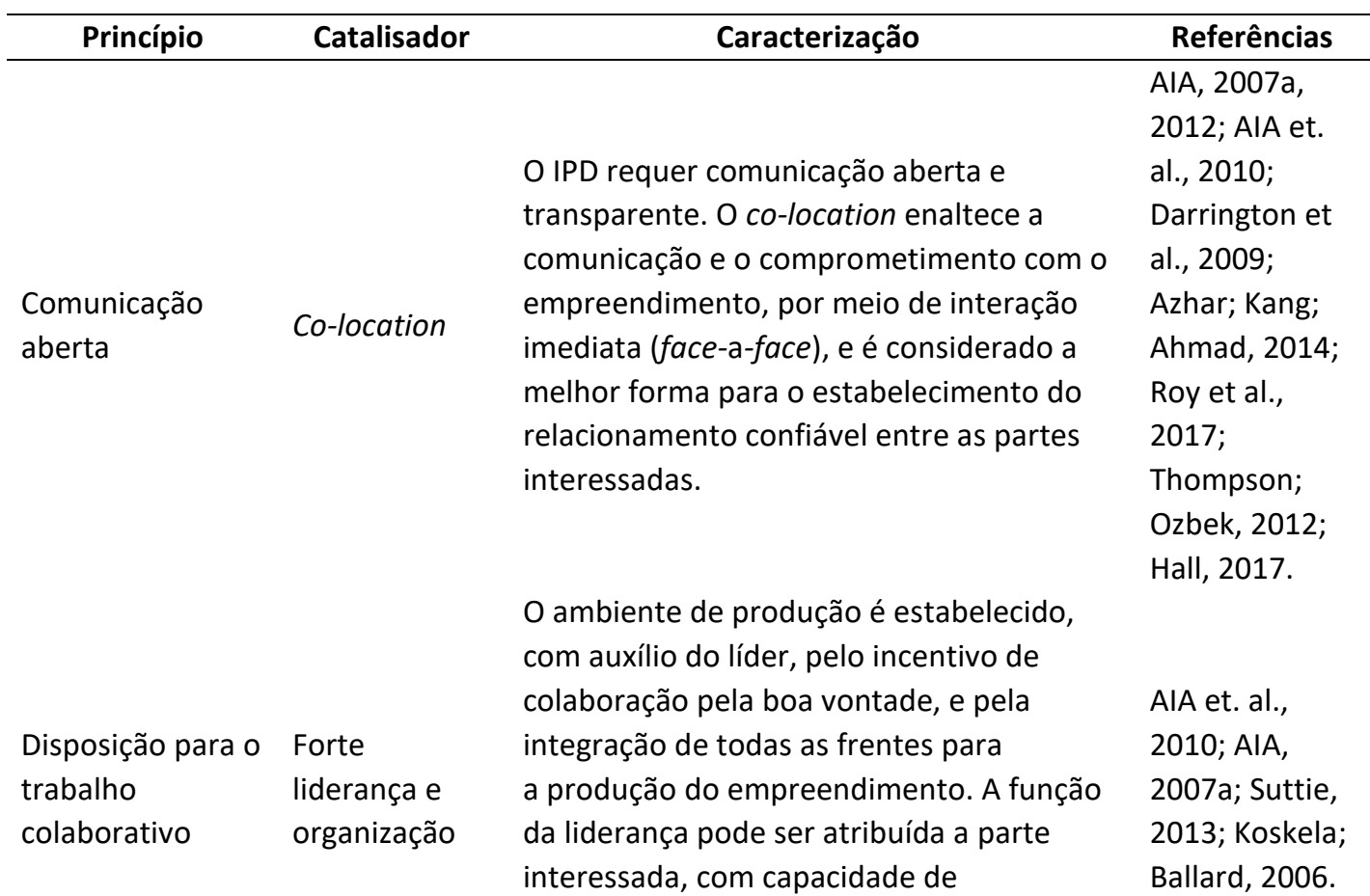

impulsionar as equipes para aumento da produtividade.

Compartilhamen

Acordos to de riscos financeiros, benefícios e recompensas

multipartes, podendo ser contratos relacionais

Proteção contra litígios (processos) e seguro entre os participanteschaves integrado do empreendime nto
O compartilhamento de riscos financeiros

e benefícios faz parte do acordo estabelecido no contrato IPD, que une todas as partes interessadas no processo, o que gera maior comprometimento e envolvimento das equipes. Entre os participantes ocorre um pensamento e comportamento "de pertencimento", que contribui para maior desempenho e comprometimento com o empreendimento.

AIA, 2007a, 2012; AIA et. al., 2010; Aziz, Hafez, 2013; Lee et al., 2014; Mesa, Molenaar, Alarcón, 2016; PishdadBozorgi, Beliveau, 2016; Wøien et al., 2016; Zaninelli, 2013.

Com a definição da responsabilidade entre os participantes-chaves, as partes interessadas concordam em não impetrar ações judiciais entre si. Neste sentido, elas são motivadas a buscar soluções para os problemas, ao invés de atribuir culpa a AlA et. al., 2010, AIA, 2012; Lee et al., 2014. 


\begin{tabular}{|c|c|c|c|}
\hline Princípio & Catalisador & Caracterização & Referências \\
\hline $\begin{array}{l}\text { Vinculação e } \\
\text { igualdade } \\
\text { contratual entre } \\
\text { os participantes- } \\
\text { chaves }\end{array}$ & $\begin{array}{l}\text { Acordos } \\
\text { multipartes, } \\
\text { podendo ser } \\
\text { contratos } \\
\text { relacionais }\end{array}$ & $\begin{array}{l}\text { No processo IPD, as partes interessadas } \\
\text { estão vinculadas a um instrumento } \\
\text { contratual único, e têm igual } \\
\text { responsabilidade pelo empreendimento, } \\
\text { na tomada de decisões e na colaboração. O } \\
\text { vínculo também pode ser estabelecido } \\
\text { apenas entre os participantes-chaves } \\
\text { (proprietário, construtora e projetista } \\
\text { principal). }\end{array}$ & $\begin{array}{l}\text { AlA et al., } \\
\text { 2010; AIA, } \\
\text { 2012; Franz; } \\
\text { Leicht, } 2012 .\end{array}$ \\
\hline $\begin{array}{l}\text { Envolvimento } \\
\text { antecipado dos } \\
\text { participantes- } \\
\text { chaves }\end{array}$ & $\begin{array}{l}\text { Esforços } \\
\text { intensivos de } \\
\text { planejamento }\end{array}$ & $\begin{array}{l}\text { Os participantes principais são envolvidos } \\
\text { o mais cedo possível no processo, de modo } \\
\text { que as decisões gerais tenham maior } \\
\text { impacto já nos estágios iniciais do } \\
\text { empreendimento. Consequentemente, as } \\
\text { atividades de planejamento são } \\
\text { intensificadas, considerando-se todas as } \\
\text { necessidades do empreendimento a partir } \\
\text { da informação disponibilizada por todos os } \\
\text { integrantes. }\end{array}$ & $\begin{array}{l}\text { AlA et. Al., } \\
\text { 2010; AIA, } \\
\text { 2007a; AIA, } \\
\text { 2012; Aziz, } \\
\text { Hafez, 2013; } \\
\text { Leicht et al., } \\
\text { 2016; Sødal et } \\
\text { al 2014; Franz, } \\
\text { Leicht, 2012. }\end{array}$ \\
\hline $\begin{array}{l}\text { Transparência } \\
\text { fiscal }\end{array}$ & $\begin{array}{l}\text { Adoção de } \\
\text { ferramentas } \\
\text { de execução } \\
\text { com base na } \\
\text { construção } \\
\text { enxuta }\end{array}$ & $\begin{array}{l}\text { A transparência fiscal enaltece a confiança } \\
\text { e mantém as contingências visíveis e } \\
\text { controláveis. Além disso, permite que as } \\
\text { equipes modifiquem e adéquem itens do } \\
\text { empreendimento a partir da agilidade na } \\
\text { alteração de custo, por meio } \\
\text { de ferramentas que contribuem para } \\
\text { intensificar a gestão e potencializar o valor } \\
\text { do produto, ao mesmo tempo em que se } \\
\text { reduz o desperdício. }\end{array}$ & $\begin{array}{l}\text { AIA et. Al., } \\
\text { 2010; AIA, } \\
\text { 2007a; AIA, } \\
\text { 2012; Al } \\
\text { Ahbabi, 2014; } \\
\text { Darrington et } \\
\text { al., 2009; Lee } \\
\text { et al., 2014. }\end{array}$ \\
\hline $\begin{array}{l}\text { Inovação e } \\
\text { decisões } \\
\text { colaborativas }\end{array}$ & $\begin{array}{l}\text { Tecnologias } \\
\text { apropriadas }\end{array}$ & $\begin{array}{l}\text { Os participantes colaboram na tomada de } \\
\text { decisões de maior impacto, e são } \\
\text { incentivados a buscar soluções inovadoras } \\
\text { para a resolução dos problemas. O sistema } \\
\text { tecnológico é especificado logo no início } \\
\text { do empreendimento, de modo a } \\
\text { maximizar a funcionalidade e interação, } \\
\text { para garantir maior efetividade } \\
\text { do planejamento e visualização } \\
\text { compreensível do empreendimento e suas } \\
\text { etapas. }\end{array}$ & $\begin{array}{l}\text { AIA et. al., } \\
\text { 2010; AIA, } \\
\text { 2007a, AIA } \\
\text { 2012; Hall, } \\
\text { 2017; Seed, } \\
\text { 2014; Fischer } \\
\text { et al., 2014; } \\
\text { Sarkar; } \\
\text { Mangrola, } \\
\text { 2016; Ashcraft } \\
\text { Jr., 2014. }\end{array}$ \\
\hline
\end{tabular}

\section{DISCUSSÃO E RESULTADO}

O processo do desenvolvimento da pesquisa seguiu uma sequência de passos que complementam o objetivo do estudo. Primeiro foi efetuada a avaliação do referencial teórico sobre o IPD (identificação dos seus elementos), em seguida, buscou-se caracterizar e avaliar a relação entre os elementos do IPD, e por fim, desenvolveu-se o mapa conceitual. As duas 
primeiras etapas foram apresentadas no item "contextualização do IPD", enquanto o desenvolvimento do mapa conceitual é apresentado na sequência.

\section{DESENVOLVIMENTO DO MAPA CONCEITUAL}

A partir da informação extraída sobre a caracterização dos princípios e catalisadores, se desenvolveu um processo interativo entre os autores do estudo e dois pesquisadores que têm domínio e conhecimento sobre métodos de gestão de empreendimentos, e adoção de alternativas que visam à modernização do processo de produção dos empreendimentos. A interação objetivou a construção do mapa conceitual, classificada como uma representação visual sobre o IPD, de modo que se obtivesse melhor percepção sobre o tema.

Assim, a primeira parte do desenvolvimento do mapa conceitual baseou-se na construção de relações. Durante a interação, foi proposta a classificação dos elementos do IPD a partir de domínios de um modelo de gestão de empreendimentos, designados como: organizacional; comercial; operacional (SEED, 2014; DARRINGTON et al., 2009). Constatou-se que o IPD procura superar sistematicamente os problemas relacionados às questões organizacionais e comerciais, e pouco foca em questões operacionais (DARRINGTON et al., 2009). Os elementos abrangem os domínios organizacional e comercial, considerando ainda os princípios comportamentais e contratuais, respetivamente (KOVACIC; MÜLLER, 2014).

No entanto, pela caracterização dos catalisadores observou-se que apesar destes pertencerem à categoria de princípios contratuais, uma parte deles influencia na operacionalização do processo de produção. Assim, para a classificação do domínio tomou-se como principal elemento o catalisador em questão. Foram consideradas três categorias para disposição e agrupamento dos elementos, sejam estes:

- Organizacional e gerencial;

- Comercial (estratégia contratual);

- Comercial (estratégia operacional).

A caracterização do catalisador evidencia informações claras em relação à sua influência dentro do domínio ao qual pertence. A Tabela 4 apresenta a disposição dos catalisadores e sua influência nos domínios classificados a partir das cores.

Tabela 4. Domínio de princípios e catalisadores.

Fonte: Autores.

\begin{tabular}{lll}
\hline \multicolumn{1}{c}{ Princípio } & \multicolumn{1}{c}{ Catalisador } & \multicolumn{1}{c}{$\begin{array}{c}\text { Fatores que condicionam a } \\
\text { seleção do domínio }\end{array}$} \\
\hline \multicolumn{1}{c}{ Organizacional e gerencial (Comportamento e comunicação) } \\
\hline $\begin{array}{l}\text { Respeito mútuo e } \\
\text { confiança }\end{array}$ & $\begin{array}{l}\text { Relacionamento pré- } \\
\text { existente entre as partes } \\
\text { interessadas }\end{array}$ & $\begin{array}{l}\text { Interação e comportamento que } \\
\text { conduz à mudança de paradigma. }\end{array}$ \\
\hline $\begin{array}{l}\text { Alinhamento de metas } \\
\text { nas fases iniciais do } \\
\text { empreendimento } \\
\text { Comunicação aberta }\end{array}$ & $\begin{array}{l}\text { Plano de incentivos } \\
\text { financeiros vinculados às } \\
\text { metas } \\
\text { Co-location }\end{array}$ & $\begin{array}{l}\text { Motivação e foco em relação à } \\
\text { meta, alinhada aos interesses } \\
\text { individuais. }\end{array}$ \\
& & $\begin{array}{l}\text { Comunicação aberta e imediata, } \\
\text { com incidência no fluxo de } \\
\text { informação e compartilhamento. } \\
\text { Disposição para o } \\
\text { trabalho colaborativo }\end{array}$ \\
\hline
\end{tabular}




\begin{tabular}{|c|c|c|}
\hline Princípio & Catalisador & $\begin{array}{l}\text { Fatores que condicionam a } \\
\text { seleção do domínio }\end{array}$ \\
\hline $\begin{array}{l}\text { Compartilhamento de } \\
\text { riscos financeiros, } \\
\text { benefícios e recompensas } \\
\text { Termo de } \\
\text { responsabilidade entre os } \\
\text { participantes-chaves }\end{array}$ & $\begin{array}{l}\text { Acordos multipartes, } \\
\text { podendo ser contratos } \\
\text { relacionais } \\
\text { Proteção contra litígios } \\
\text { (processos) e seguro } \\
\text { integrado do } \\
\text { empreendimento }\end{array}$ & $\begin{array}{l}\text { Produção aprimorada devido ao } \\
\text { acordo contratual, e focada no } \\
\text { compartilhamento dos resultados. } \\
\text { Interação e responsabilidade por } \\
\text { tudo que envolve o } \\
\text { empreendimento e renúncia dos } \\
\text { participantes-chaves em impetrar } \\
\text { processos e ações judiciais }\end{array}$ \\
\hline $\begin{array}{l}\text { Vinculação e igualdade } \\
\text { contratual entre } \\
\text { participantes-chaves }\end{array}$ & $\begin{array}{l}\text { Acordos multipartes, } \\
\text { podendo ser contratos } \\
\text { relacionais }\end{array}$ & $\begin{array}{l}\text { Igual importância no processo, e } \\
\text { remoção da possibilidade de um } \\
\text { sistema hierarquizado. }\end{array}$ \\
\hline \multicolumn{3}{|c|}{ Comercial (Estratégias operacionais) } \\
\hline $\begin{array}{l}\text { Envolvimento antecipado } \\
\text { dos participantes-chaves }\end{array}$ & $\begin{array}{l}\text { Esforços intensivos de } \\
\text { planejamento }\end{array}$ & $\begin{array}{l}\text { Foco na identificação de todas as } \\
\text { necessidades do } \\
\text { empreendimento, e precisão da } \\
\text { informação gerada. }\end{array}$ \\
\hline Transparência fiscal & $\begin{array}{l}\text { Adoção de ferramentas de } \\
\text { execução com base na } \\
\text { construção enxuta }\end{array}$ & $\begin{array}{l}\text { Aprimoramento do custo e do } \\
\text { prazo, e redução de desperdícios. }\end{array}$ \\
\hline $\begin{array}{l}\text { Inovação e decisões } \\
\text { colaborativas }\end{array}$ & Tecnologias apropriadas & $\begin{array}{l}\text { A percepção visual e dos detalhes } \\
\text { do empreendimento, e tomada de } \\
\text { decisões precisas. }\end{array}$ \\
\hline
\end{tabular}

Tabela 4. Domínio de princípios e catalisadores. (Continuação)

Fonte: Autores.

Legenda da Tabela 4:

Organizacional e gerencial com influência no comportamento e comunicação;

Comercial com influência contratual;

Comercial com influência na estratégia operacional.

Durante a análise da disposição dos catalisadores e princípios dentro dos domínios (Tabela 4), constatou-se que os catalisadores com grande influência no comportamento e comunicação, tais como co-location, relacionamento pré-existente, forte liderança e planos de incentivo, intensificam a estrutura organizacional do empreendimento. Por outro lado, os catalisadores com influência no contrato, como o acordo multiparte e proteção contratual, aumentam as chances dos requisitos comerciais serem efetivos. E por fim, os catalisadores com influência na produção, como planejamento intensificado, adoção de ferramentas de execução e tecnologias apropriadas, auxiliam na parte operacional do empreendimento.

Observou-se que existem princípios focados no processo de produção, e outros focados no contrato. Assim, os princípios que têm influência na produção foram classificados como elementos para a produção do empreendimento (cor laranja), enquanto que, os demais foram classificados como elementos conceituais e contratuais (cor cinza), conforme apresentado no mapa conceitual (Figura 6). 
Figura 6. Mapa conceitual do

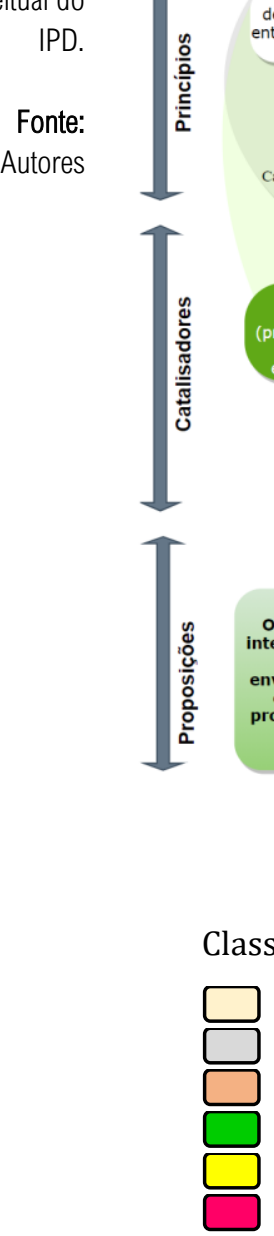

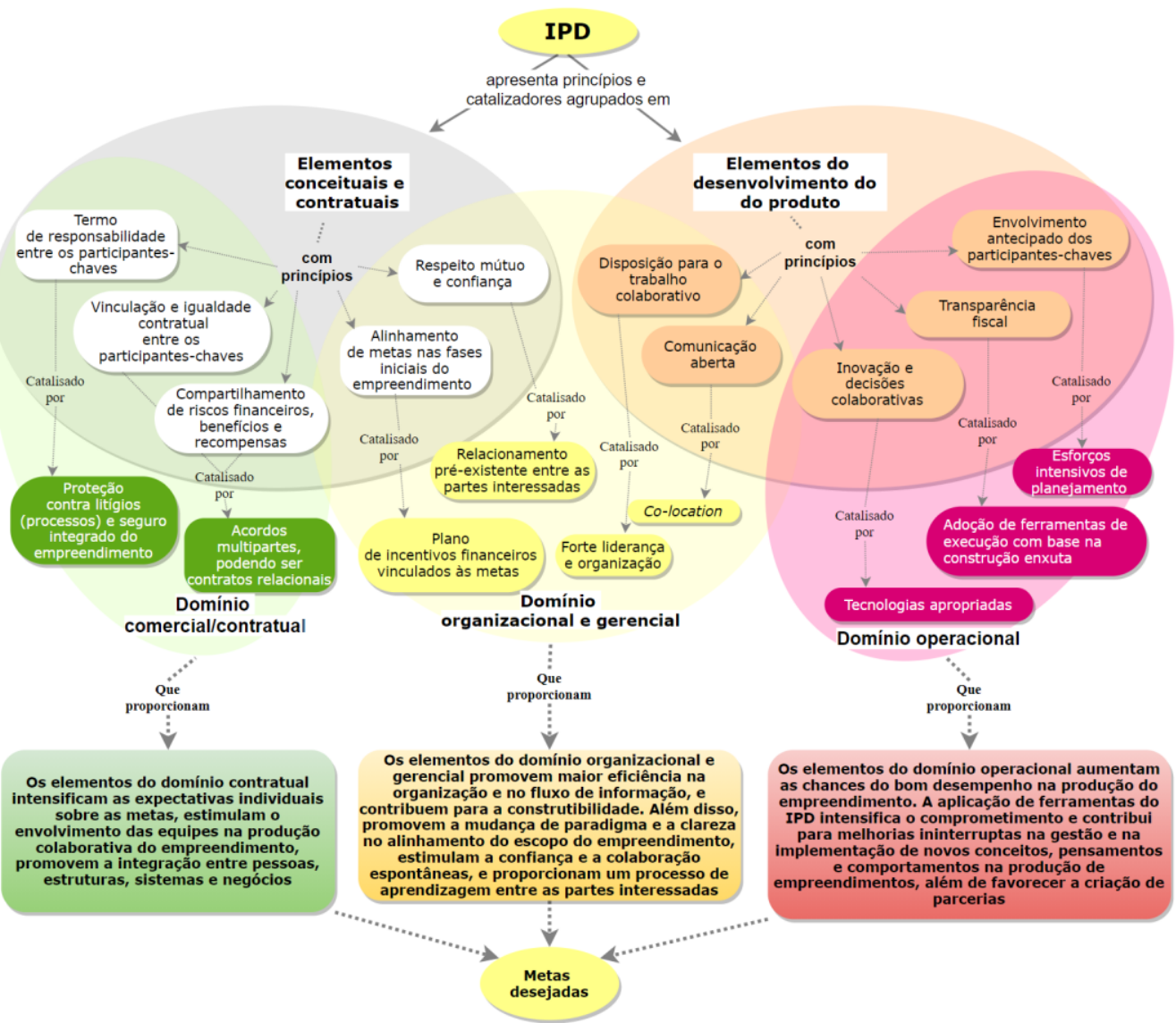

lassificação dos componentes e o MCF da Figura 6:

Início (IPD) e fim do mapa (metas desejadas);

Princípios do IPD do grupo de elementos conceituais e contratuais;

Princípios do IPD do grupo de elementos para o desenvolvimento do produto;

Catalisadores com domínio comercial/ contratual;

Catalisadores com domínio organizacional e gerencial;

Catalisadores com domínio operacional;

Ao final da construção do mapa conceitual, observou-se que os elementos pertencentes a um determinado domínio tendem a promover resultados convergentes. Assim, para o desenvolvimento das proposições sintetizou-se a informação gerada a partir de um dado grupo de elementos do IPD, que remetem aos benefícios possíveis de serem alcançados com a efetivação, tanto dos princípios, como dos catalisadores, sendo este o principal resultado do mapa conceitual.

As proposições geradas reúnem informações que podem servir de parâmetros de desempenho durante a aplicação dos princípios em empreendimentos. Ao mesmo tempo, elas demonstram que os princípios e catalisadores com domínio comercial, com influência no contrato podem intensificar as expectativas individuais sobre as metas, estimular a organização da produção, gerar integração de todo o processo, e promover interação e desempenho por meio do comprometimento em relação às metas estipuladas. Por outro lado, os princípios e catalisadores do domínio organizacional e gerencial têm influência no comportamento e comunicação, podem conduzir à maior efetividade e eficiência da organização, bem como expandir o fluxo de informação, e desempenho na produção, em um ambiente onde predominam o respeito mútuo e a confiança entre partes interessadas. Do mesmo modo, a 
organização pode enaltecer a confiança, auxiliar na mudança de paradigma, estimular a colaboração pela boa vontade, gerar clareza do escopo, aperfeiçoar o processo de produção e promover aprendizagem máxima entre partes interessadas. Por fim, os princípios e catalizadores do domínio operacional podem intensificar o comprometimento entre as partes interessadas e favorecer o estabelecimento de parcerias, além de contribuir para um processo de melhoria ininterrupta, tanto na gestão do empreendimento como na implementação de novos conceitos, pensamentos e comportamentos.

\section{CONCLUSÕES}

As evidências da literatura proporcionaram a síntese de princípios e catalisadores (Tabela 1 e Tabela 2), a partir daí proporcionar a caracterização e a organização dos elementos do IPD (Tabela 3 e Tabela 4). Com a informação e estruturação gerada foi proposto o mapa conceitual do IPD (Figura 6), que ressalta a relação entre seus princípios e catalisadores, organizados a partir das características dos domínios (comercial/contratual, organizacional e gerencial, e operacional) que o modelo demanda.

Constatou-se que existe uma flexibilidade na prescrição dos catalisadores, visto que, apesar da estrutura conceitual do IPD enfatizar o emprego específico de alguns deles, estes podem ser substituídos por outras alternativas, desde que mantenham coerência com a efetivação dos princípios vinculados a eles. No entanto, é considerável desenvolver estratégias para uma aplicação mais efetiva dos princípios necessários do IPD, dependendo do tipo de colaboração selecionada para empreendimento, almejando o alcance das proposições acopladas a eles. Além disso, observou-se que determinados elementos do IPD condicionam a aplicação dos outros, o que pode levar à atribuição de importâncias e arranjos diferenciados, considerando os aspectos importantes para um contexto específico da produção do empreendimento, e da experiência das partes envolvidas no processo.

Em geral, o IPD é um modelo de gestão de empreendimento apresentado por meio de princípios que enaltecem a produção colaborativa e integrada. A abordagem do IPD se enquadra na linha de práticas de gestão inovadoras flexíveis que podem ser combinadas com modelos de gestão já existentes, por meio dos seus princípios e catalisadores. 0 desenvolvimento de estratégias que focam na aplicação gradativa de cada um dos princípios é imprescindível em ambientes de produção onde a colaboração ainda é pouco difundida.

\section{Agradecimentos}

Esta pesquisa foi realizada com apoio da Coordenação de Aperfeiçoamento de Pessoal de Nível Superior - Brasil (CAPES) - Código de Financiamento 001. Agradecimentos aos acadêmicos que participaram da pesquisa para o desenvolvimento do mapa conceitual.

\section{Referências Bibliográficas}

ABDIRAD, H.; DOSSICK, C. S. Restructuration of architectural practice in integrated project delivery (IPD): two case studies. Engineering, Construction and Architectural Management, v. 26, n. 1, p. 104117, 2019. DOI 10.1108/ECAM-05-2018-0196.

AIA. Integrated Project Delivery: A Guide. AIA California Council, 2007a. Disponível em: Disponível em: https://www.aia.org/resources/64146-integrated-project-delivery-a-guide

AIA. Integrated Project Delivery: A Working Definition. AIA California Council, 2007b. Disponível em: aiacc http://ccas11bijagos.pbworks.com/f/IPD+Definition-AIACC.pdf 
AIA; NASFA; COAA; APPA; AGC. Integrated project delivery - IPD for Public and Private Owners: A joint effort of NASFA, COAA, APPA. Lexington, KY, 40, 2010. Disponível em: agc.org.

AIA, C. C.; AGC, A. Draft Primer on Project Delivery. AIA and AGC of America, v. 2, p. 15, 2011. Disponível em: agc.org

AIA. IPD Case Studies. School of Architecture University of Minnesota, 2012. Disponível em: agc.org

AL AHBABI, M. S. Process protocol for the implementation of integrated project delivery in the UAE: A client perspective. Ph.D. Thesis-Salford, UK: University of Salford, 2014. Disponível em: Salford

ALARCÓN, L. F.; MESA, H.; HOWELL, G. Characterization of Lean Project Delivery. In: 21TH ANNUAL CONFERENCE OF THE INTERNATIONAL GROUP FOR LEAN CONSTRUCTION, 2013. Disponível em: IGLC

ASHCRAFT Jr. H. W. The Transformation of Project Delivery. The Construction Lawyer, v. 34, n. 4, p. 35-58, 2014. Disponível em: amercanbar.org

AZIZ, R. F.; HAFEZ, S. M. Applying lean thinking in construction and performance improvement. Alexandria Engineering Journal, v. 52, n.4, p. 679-695, 2013. DOI 10.1016/j.aej.2013.04.008. Disponível em: https://doi.org/10.1016/j.aej.2013.04.008

AZHAR, N.; KANG, Y.; AHMAD, I. U. Factors Influencing Integrated Project Delivery in Publicly Owned Construction Projects: An Information Modelling Perspective. Procedia Engineering, Fourth International Symposium on Infrastructure Engineering in Developing Countries, IEDC 2013. v. 77, p. 213-221, 2014. DOI 10.1016/j.proeng.2014.07.019. Disponível em: https://doi.org/10.1016/j.proeng.2014.07.019.

BIGELOW, D. B.D. B.; ESCAMILLA E., LOCKWOOD, C. Comparison of Construction Manager at Risk and Integrated Project Delivery Performance on Healthcare Projects: A Comparative Case Study. International Journal of Construction Education and Research, v.11, n.1, p. 40-53, 2015. DOI 10.1080/15578771.2013.872734. Disponível em: https://doi.org/10.1080/15578771.2013.872734

CARVALHO, DE S. R. P.; PAULA, D.; FORTES VITOR, A.; BARICHELLO, E.; VILLAR, R. L. A.; PEREIRASANTOS, V. E.; FERREIRA-JUNIOR, M. A. Using Concept Maps: Results with Different Teaching and Learning Methods. Aquichán, v. 16, n. 3, 382-391, 2016. DOI 10.5294/aqui.2016.16.3.9. Disponível em: http://dx.doi.org/10.5294/aqui.2016.16.3.9

$\mathrm{CHOI}$, J. et al. Team Integration and Owner Satisfaction: Comparing Integrated Project Delivery with Construction Management at Risk in Health Care Projects. Journal of Management in Engineering. American Society of Civil Engineers (ASCE), v. 35, n. 1, 2019. DOI 10.1061/(ASCE)ME.19435479.0000654 .

DARRINGTON, J.; DUNNE, D.; LICHTIG, W. Organization, Operating System, and Commercial Terms. Managing Integrated Project Delivery. CMAA, McLean, Virginia, p. 10-47, 2009. Disponível em: leanconstruction.org

DE MARCO, A.; KARZOUNA, A. Assessing the benefits of the integrated project delivery method: A survey of expert opinions. In: PROCEDIA COMPUTER SCIENCE 2018, Anais: Elsevier B.V., 2018. p. 823-828. DOI: 10.1016/j.procs.2018.10.107.

DIAS, C. A. Grupo Focal: técnica de coleta de dados em pesquisas qualitativas. Revista informação sociedade, v.10, n.2, 2000. Disponível em: $\underline{\text { UFPB }}$

DURDYEV, S.; HOSSEINI, M. R.; MARTEK, I.; ISMAIL, S.; ARASHPOUR, M. Barriers to the use of integrated project delivery (IPD): a quantified model for Malaysia. Engineering, Construction and Architectural Management, v. 27, n. 1, p. 186-204, 2019. DOI 10.1108/ECAM-12-2018-0535 
ELY, D. M. Proposta de um modelo para avaliação do processo de concorrência pública de obras ou serviços de engenharia. Tese, Florianópolis: Universidade Federal de Santa Catarina, 2016. Disponível em: https://repositorio.ufsc.br/xmlui/handle/123456789/167839

ENGEB $\varnothing$, A.; LÆEDRE, O.; YOUNG, B.; LARSSEN, P. F.; LOHNE, J.; KLAKEGG, O. J. Collaborative project delivery methods: A scoping review. Journal of Civil Engineering and Management, v. 26, n. 3, p. 278-303, 2020. DOI 10.3846/jcem.2020.12186.

FERNANDO, C.K., HOSSEINI, M.R., ZAVADSKAS, E.K., PERERA, B. AND RAMEEZDEEN, R. Managing the financial risks affecting construction contractors: implementing hedging in Sri Lanka. International Journal of Strategic Property Management, v. 21, n. 2, p. 212-224, 2017. DOI 10.3846/1648715X.2017.1301592. Disponível

em: https://doi.org/10.3846/1648715X.2017.1301592

FIGUEIREDO, N. M. A. D. Metodo e metodologia na pesquisa cientifica. YENDIS, Difusão Editora, 2004, 247 p. ISBN: 9788577280858

FISCHER, M.; REED, D.; KHANZODE, D. A.; ASHCRAFT, H. A Simple Framework for Integrated Project Delivery. In: 22nd ANNUAL CONFERENCE OF THE INTERNATIONAL GROUP FOR LEAN CONSTRUCTION. P.1319-1330, Oslo, Norway, 25-27 Jun 2014. Disponível em: http://iglc.net/Papers/Details/971

FRANZ, B.; LEICHT, R. M. Initiating IPD Concepts on Campus Facilities with a Collaboration Addendum. In: CONSTRUCTION RESEARCH CONGRESS 2012: CONSTRUCTION CHALLENGES IN A FLAT WORLD. ASCE, 2012. Disponível em: CRC

GARABET, M.; MIRON, C. Conceptual map - Didactic method of constructivist type during the physics lessons. Procedia - Social and Behavioral Sciences, v. 2, n.2, p. 3622-3631, 2010. DOI 10.1016/j.sbspro.2010.03.564.

GERHARDT T. E.; SILVEIRA D. T. Métodos de pesquisa. Coordenado pela Universidade Aberta do Brasil - UAB/UFRGS e pelo Curso de Graduação Tecnológica "Planejamento e Gestão para o Desenvolvimento Rural" da SEAD/UFRGS. Porto Alegre: Editora da UFRGS, 2009. ISBN: 9788538600718.

GHASSEMI, R.; BECERIK-GERBER, B. Transitioning to Integrated Project Delivery: Potential Barriers and Lessons Learned. Lean Construction Journal, Lean and Integrated Project Delivery Special issue, p. 32-52, 2011. ISSN 1555-1369. Disponível em: Leanconstruction.org

GIL, A. C. Como elaborar projetos de pesquisa. 4. ed. São Paulo: Atlas, 2002. ISBN 8522431698.

GOLDENBERG, M. A arte de pesquisar. Rio de Janeiro: Record, 1997. ISBN 8501049654.

HALL, D. Identifying the Role of the Project Intergration Strategies in the Adoption of Systemic Innovations. In: WORKING PAPER PROCEEDINGS, EPOC. Stanford Sierra Camp, California: 2017. Disponível em: gpc.stanford

HALL, D. M.; SCOTT, W. R. Early Stages in the Institutionalization of Integrated Project Delivery. Project Management Journal, v. 50, n.2, p.128-143, 2019. DOI 10.1177/8756972818819915. Disponível em: https://doi.org/10.1177/8756972818819915.

HAMZEH, et al. Integrated project delivery as an enabler for collaboration: a Middle East perspective. Built Environment Project and Asset Management, v. 9, n. 3, p. 334-347, 2019. DOI: 10.1108/BEPAM-05-2018-0084. 
HOSSEINI, A. et al. Selection Criteria for Delivery Methods for Infrastructure Projects. Procedia Social and Behavioral Sciences, v. 226, p. 260-268, 2016. DOI 10.1016/j.sbspro.2016.06.187. Disponível em : https://doi.org/10.1016/j.sbspro.2016.06.187

HOSSEINI, M.R.; BANIHASHEMI, S.; MARTEK, I.; GOLIZADEH, H.; GHODOOSI, F. Sustainable delivery of megaprojects in iran: integrated model of contextual factors. Journal of Management in Engineering, v. 34, n. 2, p. 1-12, 2018. DOI 10.1061/(ASCE)ME.1943-5479.0000587.

IOPPI, V.; FORMOSO, C. T.; ISATTO, E. L. Barriers and opportunities for the implementation of IPD principles and LPDS practices in the management of capital industrial projects in Brazil. Ambiente Construído, v. 15, n. 4, p. 87-104, Dez, 2015. Disponível em: https://doi.org/10.1590/s167886212015000400041

JADIDOLESLAMI, S. et al. A practical framework to facilitate constructability implementation using the integrated project delivery approach: a case study. International Journal of Construction Management, 2019. DOI 10.1080/15623599.2019.1686834. Disponível em: https://doi.org/10.1080/15623599.2019.1686834.

KIM, Y.-W.; REZQALLAH, K.; LEE, H. W.; ANGELEY, J. Integrated Project Delivery in Public Projects: Limitations and Opportunity. In: IN: PROC. 24TH ANN. CONF. OF THE INT'L. GROUP FOR LEAN CONSTRUCTION. Boston, MA, USA: IGLC, 2016. Disponível em: http://iglc.net/Papers/Details/1305

KOSKELA, L.; BALLARD, G. Should project management be based on theories of economics or production? Building Research \& Information, v. 34, n. 2, p. 154-163, 1 Mar. 2006. DOI 10.1080/09613210500491480. Disponível em: http://dx.doi.org/10.1080/09613210500491480.

KOVACIC, I.; MÜLLER, C. Challenges for the Implementation of Integrated Design in the Planning Practice. Procedia - Social and Behavioral Sciences, Selected papers from the 27th IPMA (International Project Management Association), World Congress, Dubrovnik, Croatia, v. 119, p. 529538, 2014. DOI 10.1016/j.sbspro.2014.03.059. Disponível em: https://doi.org/10.1016/j.sbspro.2014.03.059.

KNAPP, S.; LONG, D.; HOWELL, G. The role of the Owner's Representative on IPD projects. 22nd ANNUAL CONFERENCE OF THE INTERNATIONAL GROUP FOR LEAN CONSTRUCTION: UNDERSTANDING AND IMPROVING PROJECT BASED PRODUCTION, IGLC 2014, June 25- 27, 2014. https://iglc.net/papers/Details/1075

LAURENT, J.; LEICHT, R. M. Practices for Designing Cross-Functional Teams for Integrated Project Delivery. Journal of Construction Engineering and Management, v. 145, n. 3, 2019. DOI 10.1061/(ASCE)CO.1943-7862.0001605.

LEE, H. W.; ANDERSON, S. M.; KIM, Y-W.; BALLARD, G. Advancing impact of education, training, and professional experience on integrated project delivery. Practice Periodical on Structural Design and Construction, v. 19, n. 1, p. 8-14, 2014. DOI 10.1061/(ASCE)SC.1943-5576.0000190. Disponível em: http://dx.doi.org/10.1061/(ASCE)SC.1943-5576.0000190

LEICHT, R. M.; MOLENAAR, K. R.; MESSNER, J. I.; FRANZ, B. W.; ESMAEILI, B. Maximizing Success in Integrated Projects: An Owner's Guide. V. 1. The Pennsylvania State University. January, 2016. Disponível em: http://bim.psu.edu/delivery

LIU, M.; GRIFFIS, F. H.; BATES, A. J. Compensation structure and contingency allocation in integrated project delivery. In 120th ASEE ANNUAL CONFERENCE AND EXPOSITION, June 23 - 26, 2013. Disponível em: ASEE 
MATTOS, M. P. et al. Building constructivist education networks in pharmaceutical deontology: Education and active devices in the art of teaching. Interface: Communication, Health, Education, $v$. 24, p. 1-15, 2020. DOI 10.1590/interface.190567. Disponível em: https://doi.org/10.1590/interface.190567.

MAXWELL, J. A. Designing a qualitative study. In: Maxwell, J. A. Qualitative Research Design: An Interactive Approach. 3a Ed. Ed.: Sage Publishing, Cp. 7, p. 214-253, 2012. DOI 10.4135/9781483348858.n7. Disponível em: http://dx.doi.org/10.4135/9781483348858.n7

MIHIC, M.; SERTIC, J.; ZAVRSKI, I. Integrated Project Delivery as Integration between Solution Development and Solution Implementation. Procedia - Social and Behavioral Sciences, v. 119, p. 557565, 2014. DOI 10.1016/j.sbspro.2014.03.062. Disponível em: https://doi.org/10.1016/j.sbspro.2014.03.062.

MOLLAOGLU-KORKMAZ, S.; MILLER, V. D.; SUN, W. Assessing key dimensions to effective innovation implementation in interorganizational project teams: An Integrated Project Delivery case. The Engineering Project Organization Journal, v. 4, n. 1, p. 17-30, 2014. DOI 10.1080/21573727.2013.855895. Disponível em: https://doi.org/10.1080/21573727.2013.855895

MESA, H. A.; MOLENAAR, K. R.; ALARCÓN, L. F. Exploring performance of the integrated project delivery process on complex building projects. International Journal of Project Management, v. 34, n. 7, p. 1089-1101, 1 out. 2016. DOI: 10.1016/j.ijproman.2016.05.007

MOYLAN, W. A.; ARAFAH, N. Integrated Project Delivery: Complicated Collaboration or Improbable Panacea. PM World Journal, v. 6, n. 7, 2017. Disponível em: PMWJ

MUIANGA, E. A. D. Modelo evolutivo para aplicação do IPD (Integrated Project Delivery) em ambientes de produção de empreendimentos onde há pouca difusão de práticas colaborativas. 2018. 251 p. Tese (doutorado) Universidade Estadual de Campinas, Faculdade de Engenharia Civil, Arquitetura U Urbanismo, Campinas, SP. http://repositorio.unicamp.br/jspui/handle/REPOSIP/333580

NAWI, M. N. M.; NIFA, F. A. A.; AHMED, V. A review of traditional project procurement towards integrated practice. American-Eurasian Journal of Sustainable Agriculture, v. 8, n. 2, p. 65-70, 2014. Disponível em: $\underline{\text { AEJSA }}$

NOVAK, J. D.; CAÑAS, J. The theory underlying concept maps and how to construct them. Technical Report IHMC CmapTools - Institute for Human and Machine Cognition. Florida, USA, p. 1-36, 2008. Disponível em: https://cmap.ihmc.us/docs/theory-of-concept-maps

OSBURN et al. Integrated project delivery: An Action Guide for Leaders. Charles Pankow Foundation, 2018. Disponível em: http://cm.hive.be.uw.edu/wpcontent/uploads/sites/29/2018/06/Pankow IPDGuide.pdf

PARK, J.; KWAK, Y. H. Design-Bid-Build (DBB) vs. Design-Build (DB) in the U.S. public transportation projects: The choice and consequences. International Journal of Project Management, v. 35, n. 3, p. 280-295, Abr. 2017. DOI 10.1016/j.ijproman.2016.10.013. Disponível em: https://doi.org/10.1016/j.ijproman.2016.10.013

PISHDAD-BOZORGI, P.; BELIVEAU, Y. J. Symbiotic Relationships between Integrated Project Delivery (IPD) and Trust. International Journal of Construction Education and Research, v. 12, n. 3, p. 179192, 2016. DOI 10.1080/15578771.2015.1118170. Disponível em: http://dx.doi.org/10.1080/15578771.2015.1118170 
RAHIM, S. A.; NAWI, M. N. M.; NIFA, F. A. A. Integrated project delivery (IPD): a collaborative approach to improve the construction industry. Advanced Science Letter, v. 22, p.1331-1335, 2016. DOI 10.1166/asl.2016.6764. Disponível em: https://doi.org/10.1166/asl.2016.6764.

RACHED, F.; HRAOUI, Y.; KARAM, A.; HAMZEH, F. Implementation of IPD in the Middle East and its challenges. In: 22nd ANNUAL CONFERENCE OF THE INTERNATIONAL GROUP FOR LEAN CONSTRUCTION, pp 293-304, Oslo, Norway, 25-27 Jun 2014. Disponível em: http://iglc.net/Papers/Details/1019.

ROY, D.; MALSANE, S.; SAMANTA, P. K. Procedural challenges in interorganizational collaboration for IPD adoption. INDIAN LEAN CONSTRUCTION CONFERENCE - ILCC Indian Institute of Technology Madras, Chennai, V. 2, P. 299-307, 2017. Disponível em: https://www.ilce.in/pdf/ILCC2017/proceedings.pdf.

RUIZ-MORENO, L.; SONZOGNO, M. C.; BATISTA, S. H. S.; BATISTA, N. A. Mapa conceitual: ensaiando critérios de análise. Ciência \& Educação (Bauru), v. 13, n.3, p. 453-463, 2007. Disponível em: http://www.redalyc.org/articulo.oa?id=251019507012.

SARKAR, D.; MANGROLA, M. Development of lean integrated project delivery model for highway projects. International Journal of Construction Project Management, v. 8, n. 1, p. 25-43, 2016. Disponível em: IJCPM.

SEED, W. R. Integrated Project Delivery Requires a New Project Manager. Presented the 22nd ANNUAL CONFERENCE OF THE INTERNATIONAL GROUP FOR LEAN CONSTRUCTION. Oslo, Norway, 25-27, p. 1447-1459, Jun 2014. Disponível em: http://iglc.net/Papers/Details/1035.

SELLTIZ, C., JAHODA, M., DEUTSCH, M., COOK, S.W. Métodos de pesquisa nas relações sociais. São Paulo: Herder, 1967.

SOUZA, N. A.; BORUCHOVITCH, E. Conceptual maps: teaching and learning strategies and an evaluative tool. Educação em Revista, v. 26, n. 3, p. 195-217, 2010. DOI 10.1590/S010246982010000300010. Disponível em: https://doi.org/10.1590/S0102-46982010000300010.

$S \varnothing D A L, A . H ., ~ L F E R E$, O., SVALESTUEN, F. \& LOHNE, J. Early Contractor Involvement: Advantages and Disadvantages for the Design Team. 22nd ANNUAL CONFERENCE OF THE INTERNATIONAL GROUP FOR LEAN CONSTRUCTION. Oslo, Norway, 25-27, p. 519-531, Jun 2014. Disponível em: http://iglc.net/Papers/Details/1003.

SUTTIE, J. B. A. The impacts and effects of Integrated Project Delivery on participating organisations with a focus on organisational culture. In: 21st ANNUAL CONFERENCE OF THE INTERNATIONAL GROUP FOR LEAN CONSTRUCTION 2013, IGLC 2013. Disponível em: http://iglc.net/Papers/Details/952.

TENG, Y.; LI, X.; WU, P.; WANG, X. Using cooperative game theory to determine profit distribution in IPD projects. International Journal of Construction Management, [S. I.], v. 19, n. 1, p. 32-45, 2019. DOI: 10.1080/15623599.2017.1358075. Disponível em: https://www.tandfonline.com/doi/full/10.1080/15623599.2017.1358075.

THOMPSON, R.; OZBEK, M. Utilization of a Co-location Office in conjunction with Integrated Project Delivery. In: 48th ASC ANNUAL INTERNATIONAL CONFERENCE PROCEEDINGS. Birmingham City University, Birmingham, UK: $2012 . \quad$ Disponivel em: http://ascpro0.ascweb.org/archives/cd/2012/paper/CPRT183002012.pdf.

VOLPATO, G. L. O método lógico para redação científica. Revista Eletrônica de Comunicação, Informação e Inovação em Saúde, v. 9, n. 1, 31 mar. 2015. 
WHANG, S. W.; PARK, K. S.; KIM, S. Critical success factors for implementing integrated construction project delivery. Engineering, Construction and Architectural Management, v. 26, n. 10, p. 24322446, 2019. DOI: 10.1108/ECAM-02-2019-0073.

WØIEN, J. et al. Partnering Elements' Importance for Success in the Norwegian Construction Industry. Energy Procedia, v. 96, p. 229-240, 2016. DOI 10.1016/j.egypro.2016.09.130. Disponível em: https://doi.org/10.1016/j.egypro.2016.09.130.

YOSHIMOTO, E. M., YOSHIMOTO, G. M. F., SANTOS, G. J. F. DOS, OLIVEIRA, M. M. Conceptual map, an academic textual genre: a proposal for retextualization of didactic texts on History. Revista Brasileira de Estudos Pedagógicos, v.97, n. 247, p.619-636, 2016. DOI 10.1590/s21766681/288136311. Disponível em: https://doi.org/10.1590/s2176-6681/288136311.

ZANINELLI, T. Information and communication management as factors that influence the innovation process in the collaborative context. Perspectivas em Ciência da Informação, v. 18, n. 2, p. 39-59, 2013. DOI 10.1590/S1413-99362013000200004. Disponivel em: https://doi.org/10.1590/S141399362013000200004.

ZHANG, L.; HUANG, S.; PENG, Y. Collaboration in Integrated Project Delivery: The Effects of Trust and Formal Contracts. EMJ - Engineering Management Journal, v. 30, n. 4, p. 262-273, 2018. DOI 10.1080/10429247.2018.1498259. Disponível em: https://www.tandfonline.com/doi/abs/10.1080/10429247.2018.1498259.

\section{Notas}

\footnotetext{
¿ Termo de responsabilidade entre os participantes-chaves é a assinatura de termo referente aos riscos assumidos pelos participantes-chaves, havendo renúncia das partes interessadas em impetrar processos e ações judiciais.
} 